\title{
Ameliorative Role of Composite Flour Against Human Maladies
}

\author{
Muhammad Hanif Mughal* \\ Homeopathic Clinic, Islamabad-Pakistan \\ *Corresponding author: Muhammad Hanif Mughal, Homeopathic Clinic, Islamabad-Pakistan
}

\begin{tabular}{l} 
ARTICLE INFO \\
Received: 幽 June 03, 2019 \\
Published: 慧 June 10, 2019 \\
\hline Citation: Muhammad Hanif Mughal. \\
Ameliorative Role of Composite Flour \\
Against Human Maladies. Biomed J \\
Sci \& Tech Res 18(4)-2019. BJSTR. \\
MS.ID.003193.
\end{tabular}

Keywords: Cereals; Wheat; Composite Flour; Diabetes; Oxidative Stress; Renal Failure

\begin{abstract}
Cereals are used by humans since long from prehistoric times and are rich sources of macro and micronutrients. They are considered as staple food and provide significant amount of proteins, carbohydrates, vitamin B and minerals. It is also source of phytochemicals which impart positive impact on health. Cereals are also rich source of carbohydrates and present numbers of anti- nutrients. Composite flour by milling of cereals is different from the ready-made mixed flour which is used in bakery products and by millers contain non-perishable constituents whereas the composite flour is the mixture of different flours of vegetables, wheat or non-wheat flour, rich in protein and starch. Composite flour significantly decreases the glucose levels and prevents from heart disease via maintaining physical property of arterial walls, suppressing the betalipoprotein -C oxidation, and proliferation of aortic smooth muscle cellular phone. Composite flour also causes momentous reduction in serum glycosylated protein levels, lipoprotein cholesterol, glycosylated albumin levels, and serum lipids levels as well as also decreases the concentrations of blood glucose. Moreover, utilization of arabinoxylan fiber markedly lowers the blood glucose level, insulin resistance, enhanced the insulin sensitivity, insulin efficiency, and provides protection from the damage of beta cells. The current review article highlights the potential and curative role of composite flour against various human maladies.
\end{abstract}

\section{Introduction}

Cereals as crops are grown throughout the temperate and tropical regions of the world and full fil the approximately fifty percent food energy requirements of population. Cereals in form of wheat, rice, maize, barley are significant source of minerals and bioactive compounds to dire human requirements. Cereals are mostly used as staple food in different regions of the world. Their grains mainly consist of three cereal grain consists of three main parts such as the endosperm (germinating seed), the germ (production of new plants), and the bran (provide protection to the grain). While, their concentrations are varied in different cereals grains with same general pattern. Wheat is the major crops after barley and oat among the cereals cultivated in the European countries and mostly consumed as staple foods [1]. Among cereals, wheat (Triticum aestivum) belongs to family gramineae and is considered second only to rice as the main human food crop. Commercially, Triticum aestivum ulgarev and Triticum turgidum durum are of most importance. It is one of substantial crop and cultivated approximately on $17 \%$ of the total land worldwide. Likewise, wheat grain is comprised of different types of tissues such as embryo portion (germ), endosperm which is fully covered by starch grains, aleurone layer (packed endosperm), and the pericarp [2].

Due to the presence of nutrients and phytochemicals, wheat become more important for the nutraceutical and functional properties. After milling, wheat has been used to prepare diverse food products such as bread for the supply of nutrients to human after milling. Wheat straw is also used as animal feed. Functional characteristics of wheat are influenced by composition, grain hardness and protein contents. Additionally, wheat also exhibits some anti-nutrional effects owing to the existence of antinutrients i.e. lectin and gluten that decrease the dysfunction and diseases in humans [3,4]. Environmental and climatic factors 
including temperature, humidity, topography, soil etc. affect the quality and yield of wheat productions. In industrial milling, bran is the by-product of wheat and significant nutritional profiling, health endorsing perspectives and further is also used to prepare multifarious food items [5]. Wheat is also prominent source of carbohydrates, protein, and fibers. The pericarp contains protein content (10\%) whereas germ and aleurone layer comprises of $30 \%$ of the total protein. Likewise, endosperm contributes approximately $74 \%$ protein contents. In conclusion, aleurone and germ layers, endosperm relatively high protein contents [6].

Barley (Hordeum vulgare L.) is one of the most ancient cereal crops grown in the world today ranking fourth among cereal grains after wheat, rice, and maize. Barley is used as animal feed $(65 \%)$, malting $(33 \%)$, and human consumption $(2 \%)$. It also prevents from cardiovascular disorder via decreasing the cholesterol concentrations and improving the glucose tolerance $[7,8]$. Mechanistically, barley flour markedly lowers the bile acids absorption, eliminates steroids, increases catabolism of cholesterol, reduces lipoprotein cholesterol secretion, enhances secretion of bile acids, and reduces the total body pool of cholesterol [9]

\section{Chemical Composition}

Considering wheat composition, wheat caryopsis is consisted of (14-16\%) outer branny husk of the grain, (starch: 81-84\%) central endosperm, and embryo portion (2-3\%), respectively. Separation of endosperm from the embryo and bran layers are mainly done by conventional milling of wheat grains [2]. Barley flour contains higher amount of soluble dietary fibers especially ß-glucans, arabinoxylans and pectin. Barley grains is composed of higher quantity of $ß$-glucans as compared to other cereals. The $ß$-glucan contents vary from 10.89-19.7 g/100g on dry wt basis whereas this increased level is significantly used in food, feed and industrial applications [10].

The chickpea (Cicer arietinum L.) is cultivated in differentregions of the world as important grain legume crop. It is also promising source of starch as major carbohydrates which is approximately $83.9 \%$ of the total carbohydrate. Chickpea seeds also consist of (21.70-23.40\%) protein, and (41.10-47.42 \%) carbohydrates. It also has high protein digestibility, consists of complex carbohydrates (low glycaemic index), enriches with minerals and vitamins. Chickpea flour is also free from anti-nutritional factors [11,12]. Additionally, it is also promising source of carbohydrates, minerals, proteins and vitamins and has significant role in daily nutrients intake of human. The carbohydrates and protein approximately constitute the $80 \%$ of the total dry seed mass. Moreover, dietary fiber in chickpea significantly lower the cholesterol level and also contain a variety of Anti-Nutritional Factors (ANF) including amylase and protease inhibitors [13].

Maize also known as Zea mays L. is an important Pakistani crop and it is the $3^{\text {rd }}$ most cultivated crop pf Pakistan after wheat and rice. It is cultivated over a huge area in Pakistan. Mostly, maize is cultivated and produced in Punjab and Khaiber Pakhtunkhwa. Maize is consumed in different forms like in food grain form and used in different food products. It is also significantly use to form forage for utilization in livestock and poultry. It is very important as a commercial crop and contribute raw material to various industries in order to produce maize starch, maize syrup, maize oil, dextrose and maize flakes. The grain of maize constitute starch in the amount of $72 \%$, protein in the amount of $10 \%$, oil in the amount of $4.8 \%$, fibre in the amount of $5.8 \%$, sugar in the amount of $3.0 \%$ and ash in the amount of $1.7 \%$. In Pakistan, its area under cultivation is 992 thousand hectares and annual production of grain is grain 751 thousand tons [14].

Oat (Avena sativa) has multifunctional features and nutritional profile due to presence of components. It is a rich source of dietary fiber particularly minerals, b-glucan, and nutrients. Oats are very beneficial in the cure of diabetes mellitus and various cardiovascular diseases. The bran of oat is a rich source of vitamin B family, fat, minerals and protein, except b-glucan which is supposed to be beneficial fiber for the health of heart. This b-glucan has exceptional therapeutic properties and it is significantly important nutrient in human diet and nutrition. Diverse effects of b-glucan in terms of physiology are connected to viscosity, insulin responses, lowering the plasma glucose and enabling high movement of bile acids to lower intestine and cause high excretion of bile acid thus lowering the cholesterol level. Furthermore, it is beneficial in the treatment of celiac disease. The consumption of oat grains and oat brans in daily diet beneficial both as nutritionally and also used as therapy against many diseases [15].

\section{Nutritional Aspects}

Cereals belong to the family Gramineae and grown for their highly nutritious edible part or grain and frequently referred as grains [16]. Cereals have been consumed directly as staple foods and indirectly as feed for livestock long ago. Cereals are considered as important food sources, and foods made of cereals are supposed to be a primary energy source, vitamin B and protein, minerals for the population globally. In general, cereals are basically economical to harvest, can store and transport easily, if preserved dry it does not deteriorate readily. Cereals are used by humans since long from prehistoric times. Cereals are rich sources of macro and micronutrients and consuming high amount of cereals has significant impact by decreasing the risk of many diseases [17].

Cereals are rich source of carbohydrates and often known with the same name, because cereals consist of almost $75 \%$ carbohydrates. Starches being the chief part of cereals present in endosperm in starch granules. Starch granules contain different ratio of amylose to amylopectin which depends on the type of cereal and its variety. In general cereal varieties, amylose starch is present in the range of $25-27 \%$ although in many varieties of waxy (corn and rice) amylopectin is the chief starch present. Cereals 
composed of proteins in the range of $6-15 \%$ [18]. Wheat contain main storage proteins in the form of glutenins gliadins whereas rice contain glutelin (oryzenin) and maize contain prolamin (zein) while barley contain glutelins and hordeins while oats contain albumin and globulins [19]. Cereals also contribute significant quantity of good quality amino acids that are building blocks of proteins, while some amino acids are limited. Diet must provide essential amino acids and from these amino acids human body can make other nonessential amino acids. Limiting amino acids are those amino acids that are present in amount less than that is required. In case of cereals, lysine is the limiting amino acid while in rye the first limiting amino acid is the tryptophan. In rice, rye, barley and other high lysine cultivars like maize, sorghum contains favourable composition of essential amino acid. Mixture of cereals and plantbased foods like beans and rice can make up for such amino acids (limiting). Cereals contain minute quantity of lipids in the range of 1- $3 \%$ in barley, rye, wheat and rice, while oats contain $5-10 \%$ and corn contain 5-9\%. This lipid is richest source of linoleic acid [20].

Cereals also contain vitamins and minerals. Cereals can also contribute to the intake of vitamin and mineral; though the content of micronutrient depends on the presence of amount of endosperm, bran and germ. Cereals do not contain vitamin B12, vitamin A \& $\mathrm{C}$, and no beta carotene despite of yellow corn. Though, cereals are source of significant amount of most B vitamin, particularly thiamine, niacin and riboflavin and contain appreciable amount of vitamin E. Cereals also contain minerals and are a rich source of potassium but are low in sodium like many plant foods. Whole grain cereals also comprise of iron, zinc and magnesium and minute quantity of numerous trace elements like selenium. Amongst the cereal grains, rice contributes highest level of selenium and provides about $10-13 \mathrm{mg}$ per $100 \mathrm{~g}$ (Table 1) [21].

Table 1: Starch composition of cereals.

\begin{tabular}{|c|c|c|}
\hline Cereal type & Starch (DM\%) & Amylose content (\%) \\
\hline Maize & 75 & 28 \\
\hline Waxy maize & 75 & 0,8 \\
\hline Sorghum & 68 & - \\
\hline Rice & 80 & 18,5 \\
\hline Wheat & 65 & 26 \\
\hline Oat & 60 & - \\
\hline Barley & 55 & 22 \\
\hline
\end{tabular}

\section{Milling of Cereals}

Milling process is the process of grinding in which grind the grain into flour and significant step in post-production of grain. This technique is used to eliminate the husk, bran layers, and then produce an edible portion in form of powder with appropriate grain size. During milling, essential bioactive compounds are affected with minor alteration [22]. Categorically, there are two types of milling one is dry milling (separation of bran from the endosperm) and other is roller milling (separation of bran from wheat grain), respectively. the grains are subjected to tempering process by spraying of water to retain moisture and then shifted to tempering bin for conditioning before milling. Pericarp and germ portion of grains absorb water to soft the endosperm for extraction purposes. In addition, it also stops the breaking of bran during separation. The conditioned grains are shifted via metal rolls rotating in opposite direction during roller milling. Afterwards, the grains are transferred into three major portions such as bran, germ, and endosperm $[23,24]$.

Regarding polyphenols, they are present approximately 20\% of total phenols in bran portion of grains. The higher antioxidant activity of bran portion is due to the presence of phenolic compounds. The antioxidant compounds are significantly present in different concentrations in different parts of the wheat grains. Temperature considerably affected the rate of particle size reduction, granulometric particle distribution, and dissociation of diverse bran layers during grinding [25]. Bran layers exhibited the thermomechanical properties due to the presence of lipid compounds in the cuticles. On other side, bran was brittle, fragmented and then rapidly lowered the particle size whereas at low temperature, disruption of bran layers is low. The conversion of faster fragmentation of bran into fine particles and composite particles were done after cryogenic milling. Bran of cereals also work as an elastoplastic due to their higher high plasticity and extensibility of inner bran layers. Different bran layers also show different extensibility at ambient temperature and generated the wide range of particle sizes. The increased antioxidant potential is linked with presence of hydroxyl group of phenolic acids [26].

The replacement of wheat flour with defatted cashew kernel flour significantly enhance the fiber, fat, ash and protein contents, and energy value in the composite flour whilst lowered the carbohydrates and water contents, respectively [27]. In another study done by Igbabul et al. [28], they evaluated that product was prepared by wheat, plantain and soy in which higher protein contents significantly affect the rheological properties of bread. A peer group of researchers Méité et al. [29], they found that preparation of composite flour by mixing of wheat grains with soya bean in resulting enhanced the lipid content.

Water is an important criterion to evaluate the water quality, texture, and taste in various food products; they substituted the wheat flour with yam and vanilla flour. The low moisture contents in the flour main prevented from the growth of mico-organims and protected from the deteriorative quality of the product. In addition, low water contents enhanced the shelf life of the product [30]. Likewise, supplementation of cashed flour in wheat flour significantly increased the ash and fiber contents. The enhanced contents exert health endorsing functions such as facilitation in digestion process and prevention from the constipation. Composite flour also play role in preventing of cancer, diabetes, and cardiovascular diseases [31]. A study conducted by Brou et al. 
[32], they explored that substitution of cereal and legumes flours momentously enhanced the oil and water absorption potential. The enhanced water holding capacity were occurred due to higher amino acids, protein contents, conformational characteristics, and degree of interaction with water, respectively [32]. Therefore, higher water holding capacity leads to better quality of bread or chapattis by enhancing or improving the freshness of the product. In food industry, oil is absorbed in the flour through capillary process and thus acts as mouth feel and flavor enhancer [33]. Moreover, Diallo et al. [34] reported the oil absorption capacity of formulations in bread. The density of composite flour is decreased with enhanced substitution rate. Likewise, Giami [35] found that decreased density of flours linked with good formulation in infant foods. Moreover, group of researchers [36] investigated that supplementation of Treculia africana flour into wheat flour lowered the density whilst composite flours exhibited the higher mineral contents as compared to wheat flour.

\section{Composite Flour}

Composite flour is different from the ready-made mixed flour which is used in bakery products and by millers contain nonperishable constituents whereas the composite flour is the mixture of different flours of vegetables, wheat or non-wheat flour, rich in protein and starch which can be used for the production of leavened products breads, pastas, porridges, unleavened baked products, snack foods. Sometimes, only flour is used as replacement-for example, tortillas and wheat-less bread from sorghum, pastas from sorghum or maize [37]. It can be defined as combination of flours such as tubers enriched with starch (sweet potato, yam, cassava), cereals (barley, rice, buckwheat, millet and maize), protein rich flours (peanut and soy), and non-wheat flour, respectively [38]. Composite flour is promising and significant source of different acidic phenolic compounds such as ferulic acid, benzoic acid sinapic acid, diferulic acids, and p- coumaric acid subsidiaries. Ferulic acid is the significant compound in tested grains with free, bound and dissolvable conjugated form. These compounds are present as bound phenolics and endure stomach and intestinal absorption to achieve the colon. It is also comprising of fibers, starches, proteins, B-complex nutrients, minerals i.e. Se, Zn, Mn, $\mathrm{Fe}, \mathrm{Mg}, \mathrm{K}$, and $\mathrm{P}$, respectively. Moreover, $\beta$-glucan and arabinoxylan fibers are linked with reduction in blood glucose level, coronary heart maladies, blood cholesterol, dyslipidemia, cardiovascular sicknesses, glycemic control, obstruction weight control, and ceaseless diseases [39].

\section{Role of Composite Flours in Food Industry}

Composite flour is the combination of different protein enriched foods and starches. The mostly used starches and protein to prepare the composite flour are jam, sweet potatoes as well as also peanut and soy, respectively. Different cereal and pulses are used to make composite flour including rice, millet, barley, maize, wheat, chickpea, and corn [37]. In recent years, consumers are diverted their attention towards ready-to-eat snacks due to lack of time and changes in lifestyle and eating habits. The production of composite flours to give a chance to the producers to attain and support their crops. Changes in pattern of life styles and shifting of large population to urban areas lead to enhance the consumption of flours to prepare the bread and other bakery commodities [40]. In developing economies, Oyeku et al. [41] documented that blended flours are good in nutrition and make them more economic due to presence of cheap ingredients. This phenomenon caused reduction in prices and are readily available. The supplementation of $30 \%$ legumes in composite flour significantly improve the quantity and quality of nutritious proteins that potential impact on nutritional status and economy of the country [42].

Composite flours play significant role by replacing wheat flour and are more economical by decreasing the wheat imports. This flour has role in confectionery products whereas deficient of essential amino acid in wheat and enrichment of threonine and lysine in pulse flours. Mixing of these flours make flour more nutritionally and economically. The composite foods functional characters are markedly enhanced with the increment of flours through addition of emulsion stability, swelling capacity and bulk density, accordingly. Composite flour is mainly used to enhance the nutritional values, and quality of the product in bakery products, in addition, it also prevents from the suffering from degenerative diseases associated with modern lifestyle [43]. They are also using to prepare the wheat flour by replacing the locally grown crops with higher protein contents. This substitution is also used to prepare the bread. The administration of corn (5\%) in wholegrain bread to enhance the hypoglycemic role due to presence of starch, dietary fiber, and high amylase content. It also maintains the quality of bread through their organoleptic and physical properties [44].

Chickpea and wheat flour have been used to enhance the utilization of indigenous food crops whereas high protein contents with wheat flour to prepare bread. The $5 \%$ chick pea addition in whole wheat bread increases the glycemic responses owing to starch, high contents of amylase, and dietary fibers, respectively. Chickpeas bioactive compounds increase the satiation, lower the appetite and improve the glycemic index in diabetic people [45].

\section{Health Perspectives}

\section{Hypoglycemic and Hypolipidemic}

Diabetes is a chronic global disease burden affecting a large segment of population, worldwide. Various mechanisms have been involved in the progression of this human syndrome, such as pancreatic $\beta$-cell dysfunction, higher concentrations of free fatty acids, insulin resistance, leading to overproduction of reactive oxygen species, as well as pancreatic $\beta$-cell deficiency and apoptosis. The diabetes is promoted the cardiovascular disease which is linked with hyperglycemia, obesity, dyslipidemia, glucose intolerance, and hypertension [46]. 
In human, consumption of arabinoxylan fibers due to their soluble nature caused momentous impact on cholesterol and the glycemic index. The high viscous substances slowed down the stomach emptying and lower the motility of the small intestine that further delayed the glucose uptake. These compounds are proven effective to prevent and control the diabetes through decreasing the blood sugar level, enhancing the insulin sensitivity, decreasing the insulin resistance, and preventing from the damage of $\beta$-cells. There are linear relationships between consumption of $\beta$-glucan and reduction in blood sugar levels and glycemic index, and enhancement in insulin levels. Being potent anti- diabetic agent, arabinogalactans reduce the diabetes complications via decreasing the glucose and insulin resistance. Cereal $\beta$-glucans have physiological properties attributed to dietary fiber, such as swelling, water retention and junction, and diffusion suppression [47]. Ahmed et al. [48] recorded significant reductions in glucose levels by psyllium fibers in diabetic rats. They also found that isoflavones prevented from heart disease via maintaining physical property of arterial walls, suppressing the beta-lipoprotein - $\mathrm{C}$ oxidation, and proliferation of aortic smooth muscle cellular phone. Furthermore, p- coumaric acids lowered the blood lipoid levels and there was inverse relation between consumption of antioxidants and incidence of CVD [48]. The administration of wheat bran in diabetic volunteers caused momentous reduction in serum glycosylated protein levels, lipoprotein cholesterol, glycosylated albumin levels, and serum lipids levels as well as also decreased the concentrations of blood glucose. Likewise, utilization of arabinoxylan fiber markedly lowered the blood glucose level, insulin resistance, enhanced the insulin sensitivity, insulin efficiency, and provide protection from the damage of beta cells. Moreover, they also lowered the postprandial blood glucose, HbA1, low density lipoprotein and enhanced the high-density lipoprotein [49].

Composite flour has been associated with a reduction in the risk of obesity, type II diabetes, insulin resistance, hypertension, heart disease, and cancer [50]. It is enriched with higher fiber contents and recognized as to improve the glucose and insulin responses, and lower serum low density lipoprotein cholesterol through enhancing digest viscosity and embedding to bile acids in the small intestine. These bindings are linked with reduction in absorption of sugar and lipids. The insoluble fibers significantly lower the blood pressure and glucose levels in human volunteers [51]. In gastrointestinal tract, bacterial fermentation of nondigestible cereals components is directly responsible for the antiinflammatory role, anti-diabetic role and cardio-protective [52]. A study explored by [53], they investigated that whole-grain diet enhanced the diversity and number of intestinal microflora as well as also showed metabolic and immunological improvements in healthy subjects [53]. Likewise, composite flours of different cereals also have been found effective against multiple human syndromes such as obesity, diabetes, cardiovascular disease, diabetes and obesity in human [54].

\section{Effect of Intake of Composite Flour on Renal Functions}

From muscle activity, creatinine is a waste product in the blood. Creatinine level becomes higher in the blood after slowing down functions of kidney. In kidney patients, whole grains-based diet should be reconsidered. Low bioavailability of whole grain phosphate is linked with high phosphate content and phytase enzyme. This enzyme is responsible to release the phosphorus from the phytate. In kidney patients, the diet should be required to give fiber contents along with health benefits and provide sufficient protein without raising the phosphorus level. Prolamines are main wheat storage protein due to higher proline and glutamine amino acids. The prolamins categorized into three groups: (i) high molecular weight glutenins, (ii) low molecular weight glutenins, and (iii) sulfur-rich gluten subunits $[55,56]$. Wheat polyphenols provide protection against oxidative damage induced by carbon tetrachloride. These bioactive compounds in cereals mitigate the lipid peroxidation and the restore the healthy kidney tissue through inhibiting the free radical production and enhancing the antioxidant enzymes activities. They have potential to initiation of radical chain reaction by deactivating the reactive free radicals [57]. Cereals compounds are promising source of saturated fatty acids and unsaturated fatty acids which exhibited anti-inflammatory role by lowering free radicals' development and Nicotinamide Adenine Dinucleotide Phosphate (NADPH) oxidase activity [58]. In addition, they also protect the body organs by reducing the pro- oxidation. In conclusion, therapeutic potential of these compounds has been found on acute renal damage [59].

Foods originating from animal sources meat, poultry, fish, eggs and dairy products are all high biological value protein foods; soya is the only high biological value food originating from a plant. Soya beans can be used as whole beans or soya sprouts, or processed as soya milk, tofu, tempeh, soya sauce or miso. The administration of wheat- soy breads (100\%) and hard wheat bread (100\%) have been found effectual to decrease the serum level of urea, creatinine and total bilirubin in experimental subjects after 4 weeks [60].

\section{Oxidative Stress}

Oxidative stress is imbalance between oxidative (production of free radicals in human body) and anti-oxidative systems of the cells and tissues. Thee free radicals embedded with lipids, proteins and nucleic acid which further linked with changed cell signaling, loss of energy metabolism, altered cellular transport mechanisms, cell cycle control, and genetic mutations as well as also lowered the biological activity, immune inflammation and activation [61]. Diabetic retinopathy remains the main source of visual deficiency in working-aged adults the world over. The diabetic macular edema and diabetic retinopathy are the serious vision compromising phases of the confusion. Hyperglycemia, oxidative pressure and provocative pathways are the vital segments that are ensnared in the prevalence of diabetic retinopathy [62]. 
Whole grain oats secure the body against age-related ailments, for example, and diabetes, cardiovascular maladies. The presence of micronutrients and fiber in different parts of wheat grain (germ and external layer) provide protection against oxidative stress. They also curtail the diabetes, obesity, and inflammations disorders. Whole grains are good and enrich source of bioactive compounds such as phenolic acids, zinc, iron, copper, selenium, manganese, phytic acid, lignins, lignans, and alkylresorcinols. All these compounds have effectual role against different types of human cancers and various syndromes. In vitro and in vivo studies, they also neutralizing or scavenging the effects of free radical production. In addition, it also enhances the cell reinforcement status due to the presence of choline, betaine, and sulfur amino acids [63-65].

\section{Conclusion}

Cereals are promising and prominent source of bioactive compounds and have been found effective to curtail various human disorders such as hyperlipidemia, obesity, diabetes complications, cancer insurgence, and cardiovascular disorder. They are good source of ferulic, p-coumaric acids polyphenols, vitamins, minerals, and arabinoxylans. The composite flour preparing by lentils, chickpea and guargum exhibited significant hypocholesterolemic effect via lowering cholesterol levels, low density lipoprotein and triglycerides concentrations, suppressing LDL-C oxidation, proliferation of aortic smooth muscle cells, and maintaining of the physical properties of arterial walls, respectively.

\section{References}

1. Oluwakemi OA, Omodele I (2015) The current status of cereal (Maize, Rice and Sorghum) crops cultivation in Africa: Need for integration of advances in transgenic for sustainable crop production. Int J Agri Policy Res 3(3): 133-145.

2. Bader Ul Ain H, Saeed F, Ahmad N, Imran A, Niaz B, et al. (2018) Functional and health-endorsing properties of wheat and barley cell wall's nonstarch polysaccharides. International Journal of Food Properties 21(1): 1463-1480.

3. Punder KD, Pruimboom L (2013) The dietary intake of wheat and other cereal grains and their role in inflammation. Nutrition 5(3): 771-787.

4. Curti E, Carini E, Bonacini G, Tribuzio G, Vittadini E (2013) Effect of the addition of bran fractions on bread properties. J Cereal Sci 57: 325-332.

5. Ferreira MSL, Martre P, Mangavel C, Girousse C, Rosa N (2012) Physicochemical control of durum wheat grain filling and glutenin polymer assembly under different temperature regimes. J Cereal Sc 56: 58-66.

6. Asseng S, Ewert F, Martre P, Rötter RP, Lobell DB, et al. (2015) Rising temperatures reduce global wheat production. Nature Climate Change 5: 143-147.

7. Baik BK, Ullrich SE (2008) Barley for food: Characteristics, improvement, and renewed interest. J Cereal Sci 48: 233-242.

8. Limberger Bayer VM, De Francisco A, Chan A, Oro T, Ogliari PJ (2014) Barley $\beta$-glucans extraction and partial characterization. Food Chem 154(1): 84-89.

9. Rincón F, Martínez B, Ibáñez MV (1998) Proximate composition and antinutritive substances in chickpea (Cicer arietinum L.) as affected by the biotype factor. J Sci Food Agric 78: 382-388.
10. Park SY, Bae IY, Lee S, Lee HG (2009) Physicochemical and hypocholesterolemic characterization of oxidized oat $\beta$-glucan. J Agric Food Chem 57(2): 439-443.

11. Arab EA, Helmy IMF, Bareh GF (2010) Nutritional evaluation and functional properties of chickpea $\mathrm{g} /$ '(Cicer arietinum L.) flour and the improvement of spaghetti produced from its. Journal of American Science 6(10): 1-32.

12. Salunkhe DK, Kadam SS (1989) Handbook of world food legumes: Nutritional chemistry, processing technology, and utilization. CRC Press: Boca Raton, FL.

13. Shimizu C, Kihara M, Aoe S, Araki S, Ito K, et al. (2008) Effect of high $\beta$-glucan barley on serum cholesterol concentrations and visceral fat area in Japanese me a randomized, double- blinded, placebo-controlled trial. Plant Foods Hum Nutr 63(1): 21-25.

14. Amagloh FK, Mutukumira AN, Brough L (2016) Carbohydrate composition, viscosity, solubility, and sensory acceptance of sweet potato- and maize-based complementary foods. Food Nutr Res 57: 18717.

15. Aman P, Rimsten L, Andersson R (2016) Molecular weight distribution of b-glucan in oat-based foods. Cereal Chem 81: 356-360.

16. Goldberg G (2015) Plants: Diet and health. The report of the British nutrition foundation task force. Blackwell, Oxford, USA.

17. Lang K, Jebb S (2015) Who consumes whole grains, and how much? Proceedings of the Nutrition Society 62: 123-127.

18. Cordain L (2014) Cereal grains: Humanity's double-edged sword. In: Evolutionary aspects of nutrition and health diet, exercise, genetics and chronic disease. Nutr Diet 84: 19-73.

19. Sadiq Butt M, Tahir-Nadeem M, Khan MK, Shabir R, Butt MS (2010) Oat: unique among the cereals. Eur J Nutr 47: 68-79.

20. Kent NL, Evers AD (2015) Kent's technology of cereals, $19^{\text {th }}$ Ed. Elsevier, Oxford. USA.

21. Serna-Saldivar SO (2010) Food preservation technology. In: Cereal grains properties, processing, and nutritional attributes. CRC Press, pp. 177-222.

22. Noort M, Van Haaster D, Hemery Y, Schols H, Hamer R (2010) The effect of particle size of wheat bran on bread quality-Evidence for fibreprotein interactions. J Cereal Sci 52(1): 59-64.

23. Stone B, Morell MK (2009) Carbohydrates: Wheat, chemistry and technology, (4 ${ }^{\text {th }}$ Ed). American Association of Cereal Chemists, St Paul, pp. e299-e362.

24. Emelike NJ T, Barber LI, Ebere CO (2015) Proximate, mineral and functional properties of defatted and undefatted cashew (Anacardium occidentale linn.) kernel flour. European Journal of Food Science and Technology 3(4): 11-19.

25. Igbabul BD, Amove J, Okoh A (2014) Quality evaluation of composite bread produced from wheat, defatted soy and banana flours. Int J Nutri Food Scie 3(5): 471-476.

26. Goesaert H, Brijs K, Veraverbeke WS, Courtin CM, Gebruers K, et al. (2005) Wheat flour constituents: how they impact bread quality, and how to impact their functionality. Trends in Food Sci Technol 16(1): 1230.

27. Keran $H$, Salkić $M$, Odobašić $A$, Jašić $M$, Ahmetović $N$, et al. The importance of determination of some physical-chemical properties of wheat and flour. Agriculturae Conspectus Scientificus 74(3): 197-200.

28. Elleuch M, Bedigian D, Roiseux O, Besbes S, Blecker C, et al. (2011) Dietary fibre and fibre-rich by-products of food processing: Characterization, technological functionality and commercial applications: A Review. Food Chem 124: 411-421. 
29. Brou K, N'Da-kouassi AM, Kouadio JH, Guehi T, N'Guessan KF, et al. (2013) Biochemical characterization and fonctional properties of weaning food made from cereals (millet, maize) and legumes (beans, soybeans). J Food Chem Nutri 1(1): 22-32.

30. Yadahally NS, Vadakkoot BS, Vishwas MP, Vasudeva S (2012) Nutrients and antinutrients in cowpea and horse gram flours in comparison to chickpea flour: Evaluation of their flour functionality. Food Chem 131 462-468.

31. Diallo KS, Soro D, Koné KY, Assidjo NE, Yao KB, et al. (2015) Fortification and substitution of the wheat flour by the flour of Voandzou (Vigna subterranea L. verdc) in the production of the bakery products. Int J Innov Sci Res 18(2): 434-443.

32. Giami SY (1993) Effect of processing on the proximate composition and functional properties of cowpea (Vigna unguiculata) flour. Food Chem 47: 153-158.

33. Akubor PI, Badifu GI O (2004) Chemical composition, functional and baking properties of African breadfruit kernel and wheat flour blends. Int J Food Sci Technol 39: 223-229.

34. Ameh MO, Gernah DI, Igbabul BD (2013) Physico-chemical and sensory evaluation of wheat bread supplemented with stabilized undefatted rice bran. Food Nutri Sci 4: 43-48.

35. Chandra S, Singh S, Kumari D (2015) Evaluation of functional properties of composite flours and sensorial attributes of composite flour biscuits. J Food Sci Technol 52(6): 3681-3688.

36. Yaver E, Bilgiçli N (2019) Effects of different dephytinisation methods on chemical properties of commercial and traditional breads prepared from composite flour. Food Chem 276: 77-83.

37. Prabhasankar P, Rajiv J, Indrani D, Venkateswara Rao G (2007) Influence of whey protein concentrate, additives, their combinations on the quality and microstructure of vermicelli made from Indian T. Durum wheat variety. J Food Eng 80: 1239-1245.

38. Trevor SK Ng, McKinley GH, Padmanabhan M (2006) Linear to nonlinear rheology of wheat flour dough. Au J Technol 9(3): 175-180.

39. Basman K (2003) Utilization of Transgluranase use to increase the leve of barley and soy flour incorporation in wheat flour breads. J Food Sci 68(8): 2453-2460.

40. Deshpande HW, Poshadri A (2013) Physical and sensory characteristics of extruded snacks prepared from Foxtail millet based composite flours. Int Food Res J 18(2): 751-756.

41. Aparana S (2018) Composite flour: A breakthrough in composite industry. IJARD 3(2): 847-850.

42. Nilufer D, Boyacioglu D, Vodovotz Y (2008) Functionality of soymilk powder and its components in fresh soy bread. J Food Sci 73: 275-281.

43. Chillo S, Falcone L, Nobile DP (2018) Influence of the addition of buckwheat flour and durum wheat bran on spaghetti quality. Journal of Cereal Science 47(2): 144-152.

44. Noorfarahzilah M, Lee JS, Sharifudin MS, Fadzelly MA, Hasmadi M (2014) Applications of composite flour in development of food products. Int Food Res J 21(6): 2061.

45. Duru KC, Kovaleva EG, Danilova IG, Van der Bijl P, Belousova AV (2018) The potential beneficial role of isoflavones in type 2 diabetes mellitus. Nutr Res 59: 1-15.

46. Biliaderis CG, Marta SI (2007) Cereal $\beta$-Glucans. Boca Rotan, CRC Press; p. 1-73.

47. Ahmed I, Naeem M, Shakoor A, Ahmed Z, Iqbal HM N (2010) Investigation of anti-diabetic and hypocholesterolemic potential of psyllium husk fiber (Plantago psyllium) in diabetic and hypercholesterolemic albino rats. Int J Biol Life Sci 6: 185-189.
48. Mani I, Mani UV (1987) Effect of wheat bran supplementation on blood sugar, glycosylated protein and serum lipids in NIDDM subjects. Plant Foods for Human Nutrition 37: 161-168.

49. Nettleton JA, Steffen LM, Loehr LR, Rosamond WD, Folsom AR (2008) Incident heart failure is associated with lower whole-grain intake and greater high-fat dairy and egg intake in the Atherosclerosis Risk in Communities (ARIC) study. J Am Diet Assoc 108: 1881-1887.

50. Flint HJ, Duncan SH, Scott KP, Louis P (2007) Interactions and competition within the microbial community of the human colon: links between diet and health. Environ Microbiol 9: 1101-1111.

51. Louis P, Scott KP, Duncan SH, Flint HJ (2007) Understanding the effects of diet on bacterial metabolism in the large intestine. J Appl Microbiol 102: 1197-1208.

52. Nilsson AC, Ostman EM, Holst JJ, Björck IM (2008) Including indigestible carbohydrates in the evening meal of healthy subjects improves glucose tolerance, lowers inflammatory markers, and increases satiety after a subsequent standardized breakfast. J Nutr 138: 732-739.

53. Inés Martínez, James M Lattimer, Kelcie L Hubach, Jennifer A Case, Junyi Yang, et al. (2013) Gut microbiome composition is linked to whole graininduced immunological improvements. ISME J 7: 269-280.

54. Zhang P, Dreisigacker S, Melchinger AE, Reif JC, Kazi AM, et al. (2005) Quantifying novel sequence variation and selective advantage in synthetic hexaploid wheats and their backcross-derived lines using SSR markers. Molecular Breeding 15(1): 1-10.

55.Zimmermann TS, Lee AC, Akinc A, Bramlage B, Bumcrot D, et al. (2006) RNAi-mediated gene silencing in non- human primates. Nature 441(7089): 111.

56. Ismael OE, Hashish EA, Ali HA (2014) Lipid profile and lipogensis following corn oil, truffle oil or wheat germ oil administration in albino rat. Global Veterinaria 12: 461-469.

57. Abd-El-Hameed AM A, Soliman HA, El-Reheem ES A (2013) Protective role of wheat germ oil in clozapine-induced oxidative stress and biochemical alterations in liver of male albino rats. J American Sci 9.

58. Durak D, Kalender S, Uzun F, Demir F, Kalender Y (2010) Mercury chloride-induced oxidative stress and the protective effect of vitamins $C$ and $\mathrm{E}$ in human erythrocytes in vitro. Afr J Biotechnol 9: 488-495.

59. Rani V, Deep G, Singh RK, Palle K, Yadav UC (2016) Oxidative stress and metabolic disorders: Pathogenesis and therapeutic strategies. Life Sci 148: 183-193.

60. Sahajpal NS, Goel RK, Chaubey A, Aurora R, Jain SK (2019) Pathological perturbations in diabetic retinopathy: Hyperglycemia, AGEs, oxidative stress and inflammatory pathways. Curr Protein Pept Sci 20(1): 92-110.

61. Filipčev B, Kojić J, Krulj J, Bodroža-Solarov M, Ilić N (2018) Betaine in cereal grains and grain-based products. Foods 7(4): 49.

62. Olaoye OA, Onilude AA, Idowu OA (2006) Quality characteristics of bread produced from composite flours of wheat, plantain and soybeans. J Biotechnol 11: 1102-1106

63. Noor A, Noor MA (2012) Physicochemical and organoleptic properties of cookies incorporated with legume flour. Int Food Res J 19(4): 15391543.

64. Hasmadi M, Siti Faridah A, Salwa I, Matanjun P, Abdul Hamid M, et al. (2014) The effect of seaweed composite flour on the textural properties of dough and bread. Journal of Applied Phycology 26: 1057-1062.

65. Shi W, Hou T, Liu W, Guo D, He H (2007) The hypolipidemic effects of peptides prepared from Cicer arietinum in ovariectomized rats and HepG2 cells. J Sci Food Agric 99(2): 576-586. 
ISSN: 2574-1241

DOI: 10.26717/BJSTR.2019.18.003193

Muhammad Hanif Mughal. Biomed J Sci \& Tech Res

(C) This work is licensed under Creative

Submission Link: https://biomedres.us/submit-manuscript.php

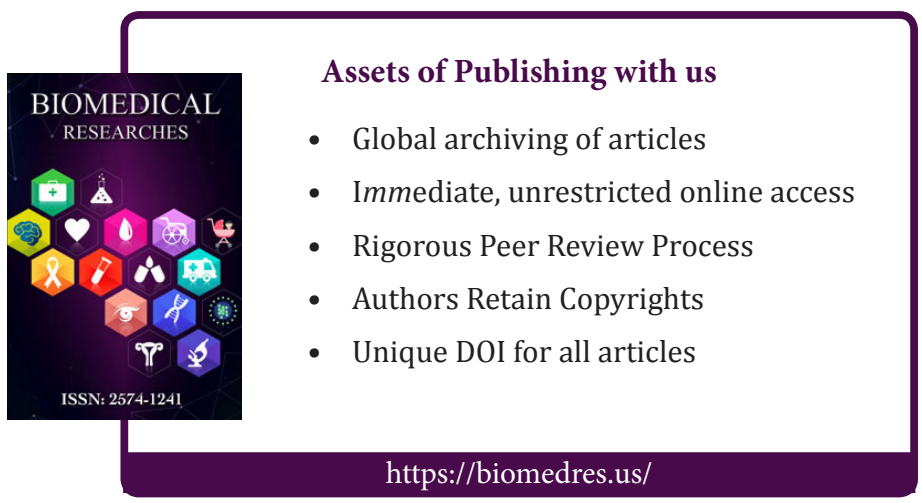

